\title{
Retrograde Coronary Venous Infusion as a Delivery Strategy in Regenerative Cardiac Therapy: an Overview of Preclinical and Clinical Data
}

\author{
Wouter A. Gathier $^{1}$ • Dirk Jan van Ginkel ${ }^{1} \cdot$ Mira van der Naald $^{1} \cdot$ Frebus J. van Slochteren $^{1} \cdot$ Pieter A. Doevendans $^{1,2}$. \\ Steven A. J. Chamuleau ${ }^{1,2}$
}

Received: 23 October 2017 / Accepted: 4 January 2018 / Published online: 1 February 2018

(C) The Author(s) 2018. This article is an open access publication

\begin{abstract}
An important aspect of cell therapy in the field of cardiac disease is safe and effective delivery of cells. Commonly used delivery strategies such as intramyocardial injection and intracoronary infusion both present with advantages and disadvantages. Therefore, alternative delivery routes are explored, such as retrograde coronary venous infusion (RCVI). Our aim is to evaluate safety and efficiency of RCVI by providing a complete overview of preclinical and clinical studies applying RCVI in a broad range of disease types and experimental models. Available data on technical and safety aspects of RCVI are incomplete and insufficient. Improvement of cardiac function is seen after cell delivery via RCVI. However, cell retention in the heart after RCVI appears inferior compared to intracoronary infusion and intramyocardial injection. Adequately powered confirmatory studies on retention rates and safety are needed to proceed with RCVI in the future.
\end{abstract}

Keywords Cell therapy $\cdot$ Myocardial infarction $\cdot$ Heart failure $\cdot$ Retrograde coronary venous infusion

$\begin{array}{ll}\text { IC } & \text { Intracoronary } \\ \text { IM } & \text { Intramyocardial } \\ \text { LVEF } & \text { Left ventricular ejection fraction } \\ \text { MVO } & \text { Microvascular obstruction } \\ \text { RC } & \text { Retrograde cardioplegia } \\ \text { RCVI } & \text { Retrograde coronary venous infusion }\end{array}$

IC Intracoronary

IM Intramyocardia

LVEF Left ventricular ejection fraction

RC Retrograde cardioplegia

RCVI Retrograde coronary venous infusion

\begin{abstract}
Abbreviations
AMI Acute myocardial infarction

CCS Canadian Cardiovascular Society scale

$\mathrm{CHF}$ Congestive heart failure

CMI Chronic myocardial infarction

CRA Chronic refractory angina

CS Coronary sinus
\end{abstract}

Associate Editor Adrian Chester oversaw the review of this article

Electronic supplementary material The online version of this article (https://doi.org/10.1007/s12265-018-9785-1) contains supplementary material, which is available to authorized users.

Steven A. J. Chamuleau

S.A.J.Chamuleau@umcutrecht.nl

1 Department of Cardiology, Division Heart and Lungs, University Medical Center Utrecht, Heidelberglaan 100, 3584

CX Utrecht, The Netherlands

2 Regenerative Medicine Center Utrecht, Uppsalalaan 8, 3584 CT Utrecht, The Netherlands

\section{Introduction}

Cell therapy has proven to be safe and feasible for treatment of cardiac disease. Yet, the clinical relevance of cell therapy is uncertain. Recent meta-analyses show a marginal $(2-5 \%)$ increase of cardiac function measured by left ventricular ejection fraction (LVEF) $[1,2]$. Taking into account the dynamic nature and the high perfusion characteristics of the cardiac tissue [3], an important aspect of cell therapy is the location and mode of delivery. Two commonly used administration techniques are intramyocardial (IM) injection and intracoronary (IC) infusion $[1,2]$. IM injection has the benefit of targeted delivery of cells in a target region, e.g., the border zone of the infarct [4], but this procedure is time-consuming, suffers from rapid wash-out of cells via venous drainage after injection [3], and needs specific systems in the catheterization laboratory. IC infusion is quick and easy to perform 
but the coronary system is often diseased in the target population, leading to inaccessibility of coronary arteries. Manipulation inside the coronary artery can potentially induce embolisms leading to decreased coronary blood flow [5-7]. Therefore, alternative delivery routes are explored. The coronary venous system is easily accessible and typically free of atherosclerotic disease. Retrograde coronary venous infusion (RCVI) is considered to be a good alternative to IM and IC administration. RCVI is performed by placing a balloon-catheter in the coronary sinus (CS) or into one of the coronary veins. In order to maximize the therapeutic potential, the balloon is kept inflated temporarily to prevent the loss of infused cells due to antegrade venous flow and to allow the cells to disseminate in the heart. For optimal effect, this occlusion is often prolonged for a certain period after cell infusion. Our aim is to provide a complete overview of preclinical and clinical studies applying RCVI as a cell delivery strategy and focus on safety aspects and efficiency measures.

\section{Methods}

\section{Search Strategy and Eligibility}

The full search strategy is available as Online Resource 1. In brief, we have performed a search using the PubMed and Embase databases on May 15, 2017. Trials were eligible for inclusion if they met the following criteria: (1) original (preclinical or clinical) study, (2) full text available in English, (3) covering cell therapy, (4) investigating safety or efficacy of retrograde CS/venous administration. An additional cross-reference screening was performed of included articles. The flowchart of the search is presented in Fig. 1.

\section{Results}

\section{Search Results}

The entire search yielded a total of 4333 (3451 Medline and 882 Embase) hits, of which 110 reports were removed after duplicate screening. Another 4155 reports were excluded after title/abstract screening because they did not fulfill the inclusion criteria. The remaining 68 articles were screened on the availability of full text, leading to another 42 exclusions. One article was excluded due to a shared dataset [8]. The cross-reference screening led to one additional inclusion that did not come up in the original search due to the absence of one part of the search string in the title and abstract [9]. The total number of

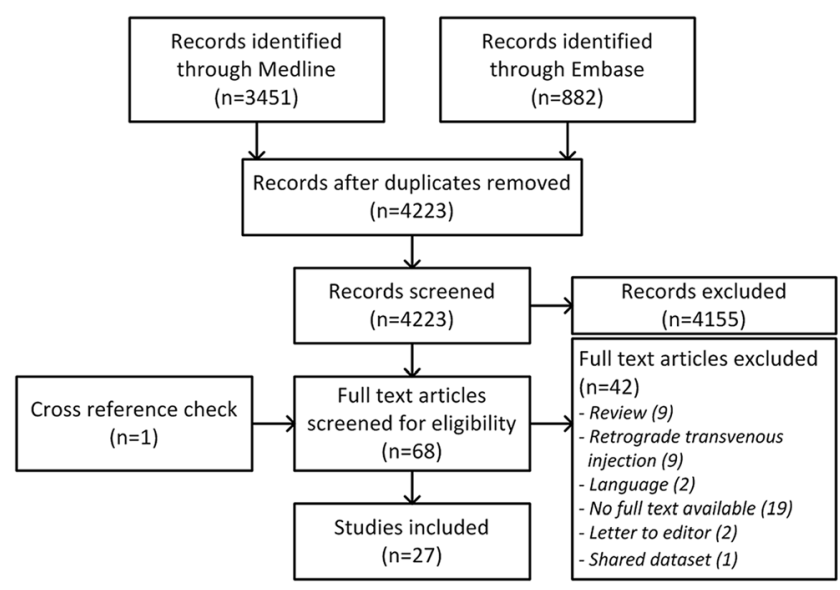

Fig. 1 Flowchart of the systematic search

articles included in this review is 27 (Fig. 1). All articles were published between 2003 and 2016.

\section{Preclinical and Clinical Experience}

Retrograde coronary venous infusion has been performed in a number of different studies. In total, 21 preclinical studies are included in this review; 8 rat studies [10-17], 3 dog studies [18-20] and 10 pig studies [9, 21-29]. Patients were treated in 6 studies [30-35].

Preclinical Experience Treatment was given in acute (acute myocardial infarction (AMI)) [9, 13-15, 19, 20, 22-25, 29] and chronic setting (chronic myocardial infarction (CMI)) [10-12, 17, 21, 26-29] and in chronic heart failure (CHF) [18]. One study treated healthy subjects $(n=1)$ [16]. Cell products administered included skeletal myoblasts $(n=6)$ $[10,12,15,16,21,26]$, bone marrow mononuclear cells $(n=2)[11,29]$, peripheral blood mononuclear cells $(n=2)$ [22, 24], adipose-derived stem cells $(n=3)$ [18, 23, 24], mesenchymal stem cells $(n=6)[13,14,19,20,25,27]$, embryonic endothelial progenitor cell $(n=1)$ [9], autologous unfractionated bone marrow $(n=1)$ [28], and cardiac explant-derived c-Kit+ cells $(n=1)$ [17]. One study administered both adipose-derived stem cells and peripheral blood mononuclear cells [24].

Clinical Experience In the clinical setting, treatment was given in AMI [31], CHF [30, 32], and chronic refractory angina (CRA) [33-35]. Infused cell products included bone marrow mononuclear cells $(n=3)[30,31,33]$, umbilical cord subepithelial cells $(n=1)$ [32], and autologous unfractionated bone marrow $(n=2)[34,35]$.

Table 1 shows study characteristics on disease model, recipients, and used cell type and number. In summary, there is broad experience with RCVI across species, disease models, and used cells. 
Table 1 Practical aspects of RCVI regarding disease type, location of infusion, and infused cell type and number

\begin{tabular}{|c|c|c|c|c|c|c|c|}
\hline & Study & Species & $\begin{array}{l}\text { Number of } \\
\text { subjects }\end{array}$ & Model & Administration & Cell type & Number of cells \\
\hline \multirow[t]{8}{*}{ Small animals } & Di Lascio [10] & Rat & 66 & CMI & $\mathrm{RCV}$ & SMB & $2 \times 10^{\wedge} 6 / 100 \mathrm{~g}$ \\
\hline & Fukushima [11] & Rat & 35 & CMI & $\mathrm{RCV}$ & BMMNC & $10^{\wedge} 7$ \\
\hline & Fukushima [12] & Rat & 85 & CMI & $\mathrm{RCV}$ & SMB & $5 \times 10^{\wedge} 6$ \\
\hline & Huang [13] & Rat & 90 & AMI & $\mathrm{RCV}$ & MSC & $10^{\wedge} 6$ \\
\hline & Huang [14] & Rat & 38 & AMI & $\mathrm{RCV}$ & MSC & $10^{\wedge} 6$ \\
\hline & Suzuki [15] & Rat & 62 & AMI & $\mathrm{RCV}$ & SMB & $10^{\wedge} 6$ \\
\hline & Suzuki [16] & Rat & 20 & NP & $\mathrm{RCV}$ & SMB & $10^{\wedge} 6$ \\
\hline & Zakharova [17] & Rat & 32 & CMI & $\mathrm{RCV}$ & CEDC & $10^{\wedge} 6$ \\
\hline \multirow[t]{13}{*}{ Large animals } & Pogue [18] & Dog & 15 & $\mathrm{CHF}$ & $\mathrm{RCV}$ & $\mathrm{ASC}$ & $10^{\wedge} 7$ \\
\hline & Sun [19] & Dog & 28 & AMI & $\mathrm{RCV}$ & MSC & $10^{\wedge} 7$ \\
\hline & Wang [20] & Dog & 18 & AMI & $\mathrm{RCV}$ & MSC & $10^{\wedge} 8$ \\
\hline & Formigli [21] & Pig & 15 & CMI & $\mathrm{RCV}$ & SMB & $8 \times 10^{\wedge} 7$ \\
\hline & Hagikura [22] & Pig & 15 & AMI & $\mathrm{RCV}$ & PBMNC & $5 \times 10^{\wedge} 6$ \\
\hline & Hong [23] & Pig & 7 & AMI & $\mathrm{RCV}$ & ASC & $10^{\wedge} 7$ \\
\hline & Hou [24] & Pig & 5 & AMI & $\mathrm{RCV}$ & $\mathrm{PBMNC} / \mathrm{ASC}$ & $10^{\wedge} 7$ \\
\hline & Kupatt [9] & Pig & $\mathrm{ns}$ & AMI & $\mathrm{RCV}$ & EEPC & $5 \times 10^{\wedge} 6$ \\
\hline & $\mathrm{Lu}[25]$ & Pig & 36 & AMI & $\mathrm{RCV}$ & MSC & $10^{\wedge} 8$ \\
\hline & Prifti [26] & Pig & 15 & CMI & $\mathrm{RCV}$ & SMB & Ns \\
\hline & Sato [27] & Pig & 13 & CMI & $\mathrm{RCV}$ & MSC & $10^{\wedge} 7$ \\
\hline & Vicario [28] & Pig & 16 & CMI & $\mathrm{RCS}$ & AUBM & Ns \\
\hline & Yokoyama [29] & Pig & 21 & AMI \& CMI & $\mathrm{RCV}$ & BMMNC & $3.2 \pm 1.2 \times 10^{\wedge} 9$ \\
\hline \multirow[t]{6}{*}{ Clinical trials } & Patel [30] & Human & 46 & $\mathrm{CHF}$ & $\mathrm{RCS}$ & BMMNC & $3.7 \times 10^{\wedge} 9$ \\
\hline & Silva [31] & Human & 9 & AMI & $\mathrm{RCV}$ & BMMNC & $10^{\wedge} 8$ \\
\hline & Tuma [33] & Human & 14 & CRA & RCS & BMMNC & $8.2 \times 10^{\wedge} 8$ \\
\hline & Tuma [32] & Human & 18 & $\mathrm{CHF}$ & RCS & UCSEC & $1 \times, 2 \times, 4 \times 10^{\wedge} 8$ \\
\hline & Vicario [34] & Human & 14 & CRA & RCS & AUBM & 0,04 or $0,08 \times 10^{\wedge} 8 / \mathrm{kg}$ \\
\hline & Vicario [35] & Human & 15 & CRA & $\mathrm{RCS}$ & AUBM & $>0,04 \times 10^{\wedge} 8 / \mathrm{kg}$ \\
\hline
\end{tabular}

$C M I$ chronic myocardial infarction (administration of cells $>1$ week post MI), $A M I$ acute myocardial infarction (administration of cells up to 7 days post $\mathrm{MI}), C H F$ chronic heart failure, $N P$ no pathology, $C R A$ chronic refractory angina, $M I$ myocardial infarction, $S M B$ skeletal myoblasts, $B M M N C$ bone marrow mononuclear cells, $P B M N C$ peripheral blood mononuclear cells, $A S C$ adipose-derived stem cells, $M S C$ mesenchymal stem cells, EEPC embryonic endothelial progenitor cells, UCSEC umbilical cord subepithelial cells, AUBM autologous unfractionated bone marrow, $C E D C$ cardiac explant-derived c-Kit+ cells, $R C V$ retrograde coronary venous infusion, $R C S$ retrograde coronary sinus infusion, $n s$ not specified

\section{Practical Aspects of RCVI}

There is a high degree of heterogeneity in the way that RCVI is performed. Important differences between models are (1) the infusion duration, (2) the volume of infused cell suspension, (3) the time that the CS or coronary vein is occluded to prevent cells from draining directly into the right atrium, (4) the number of cells infused, and (5) the location of infusion (Tables 1 and 2).

\section{Preclinical Experience}

Cells are predominantly infused via the coronary veins in preclinical trials. The infused cell number ranged from approximately $1 \times 10^{\wedge} 6$ to $3 \times 10^{\wedge} 9$. Infusion duration, infused cell volume, and the time that the CS or coronary vein was occluded differed both within and between animal species (Tables 1 and 2).

\section{Clinical Experience}

In clinical trials, cells were mainly infused via the CS. The amount of cells infused was generally higher, ranging from approximately $1 \times 10^{\wedge} 8$ to $4 \times 10^{\wedge} 9$ cells. Notable differences between preclinical and clinical trials are that infused cell volumes were many times greater in clinical trials compared to preclinical trials and that the CS or coronary vein was occluded longer in clinical trials (Tables 1 and 2).

We found a striking reporting difference regarding practical aspects of RCVI, with roughly $20 \%$ of studies not adequately 
Table 2 Heterogeneity regarding practical aspects of RCI both within and between species

\begin{tabular}{llll}
\hline Study type & Infusion duration $(\mathrm{min})$ & Infused volume $(\mathrm{ml})$ & Occlusion time $(\mathrm{min})$ \\
\hline Rat studies $(n=8)$ & $1.0[0.5-1.0](n=3)$ & $1.0[0.5-1.0](n=8)$ & $5.0[1.0-5.0](n=8)$ \\
Dog studies $(n=3)$ & No data $(n=0)$ & $10.0[10.0-20.0](n=3)$ & Insufficient data $(n=2)$ \\
Pig studies $(n=10)$ & $10.0[0.25-40.0](n=9)$ & $15.0[10.0-25.0](n=10)$ & $10.0[5.0-20.0](n=7)$ \\
Human studies $(n=6)$ & $5.0[4.0-6.0](n=6)$ & $60.0[40.25-120.0](n=6)$ & $15.0[11.0-17.0](n=5)$ \\
Overall $(n=27)$ & $5.0[0.88-11.25(n=18)$ & $10 \mathrm{ml}[1.0-40.0](n=27)$ & $10.0[5.0-12.75](n=22)$ \\
\hline
\end{tabular}

Data are presented as median with interquartile ranges calculated using IBM SPSS statistics 21

min minute(s), $m l$ milliliter(s), $n$ number of studies that statistics are based on describing procedural characteristics. This hampers the possibility to repeat certain experiments if desired.

\section{Safety Issues}

Here, safety is described as occurrence of arrhythmias related to RCVI, elevation of heart enzymes, cardiac tamponade, presence of pericardial fluid, microvascular obstruction (MVO), damage to the CS, and mortality. It should be noted that some studies did not report safety aspects due to the purpose and setup of these studies.

\section{Safety Aspects Other than Mortality}

Preclinical Experience Thirteen preclinical studies reported safety aspects of RCVI. One study only described that RCVI is safe without providing data on safety [29]. Seven studies only reported absence of arrhythmias without providing indepth data [10, 14-16, 22, 26, 28]. Five articles provided more in-depth data on safety aspects of RCVI [11, 12, 18, 20, 23]. These five studies will be discussed in more detail below.

In two studies, IM injection was associated with an increased chance of both spontaneous ventricular tachycardias and ventricular premature contractions after cell administration compared to RCVI, suggesting that RCVI is safer in these experimental models $[11,12]$. Another study closely monitored dogs for occurrence of arrhythmias and reported transient atrial fibrillation during CS catheterization in 6 out of 15 dogs and a pre-existent ventricular arrhythmia in one dog [18]. In another dog study, no occurrence of arrhythmias or cardiac tamponade associated with RCVI was seen [20]. RCVI did not lead to MVO after cell administration in one pig study [23].

Clinical Experience All six clinical studies reported safety aspects of RCVI. Two studies only reported absence of arrhythmias without providing in-depth data $[34,35]$. The other four studies provided more in-depth information on safety. In one clinical trial, absence of arrhythmias associated with RCVI was reported, but a rise in cardiac enzymes was seen in some patients after RCVI [30]. Rise in cardiac enzymes after RCVI was also reported in some patients in another clinical trial [31]. In a population of patients with heart failure, a transient increase in Troponin-I levels was seen in all patients that resolved within $24 \mathrm{~h}$ after catheterization. No arrhythmias were seen in this patient population and there was no evidence of damage to the CS after infusion [32]. No occurrence of arrhythmias, no rise in cardiac enzymes, and no pericardial effusion after retrograde delivery of cells was seen in patients with chronic refractory angina [33].

\section{Mortality}

Preclinical Experience Mortality rates were reported in 16 articles, with no RCVI-related deaths occurring in 11 of these 16 studies. The available mortality data are difficult to interpret because it is likely that other factors besides RCVI, such as surgical procedure, have had influence on mortality rates. Loss of subjects that could possibly be attributed to RCVI was seen in 5 studies, described below.

A loss of 11/66 rats (16.7\%) after RCVI was seen in one study. This loss could be attributed to the fact that a thoracotomy was performed to access the coronary vein and might not be related to the RCVI procedure itself. Since all animals received cells through RCVI, there is no control group for mortality [10]. A comparison was made between mortality rates after IM injection and RCVI in two rat studies. Mortality rates were comparable between IM injection and RCVI with the first study showing mortality rates of $2 / 34$ rats (5.9\%) after IM injection and 2/35 rats (5.7\%) after RCVI [11]. Similar results were seen in the second study with a mortality of $4 / 48$ rats $(8.3 \%)$ in the IM injection group compared to $4 / 49$ rats $(8.2 \%)$ in the RCVI group [12]. Surgical stress and bleeding were suggested to be the cause of mortality. A common complication with RCVI in small animals is sustained bleeding from the catheter insertion site because the catheter has to be inserted into the fragile left cardiac vein via the left superior vena cava or CS. A comparison was made between conventional RCVI and a modified method of RCVI to see if bleeding could be limited in small animals. Conventional RCVI was described as delivery of cells by direct insertion of a catheter in the left cardiac vein via the 
CS. Modified RCVI was described as cardiac vein catheterization via the left internal jugular vein. A mortality of $3 / 7$ rats $(42.9 \%)$ was seen in the group that received cells via conventional RCVI versus $0 / 20$ rats $(0 \%)$ in the group with modified RCVI [14]. One small animal study reported a loss of $18 / 62$ rats (29\%) within $24 \mathrm{~h}$ after RCVI, which the authors linked to development of acute heart failure rather than the RCVI [15].

Clinical Experience In all six clinical trials, mortality rates were reported but mortality related to RCVI did not occur.
In conclusion, there seems to be no relation between the way RCVI is performed and the occurrence of adverse events, arrhythmias, and mortality. Especially large animal studies and clinical trials do not report mortality or arrhythmias related to RCVI. Although RCVI is reported to be safe in the majority of studies presented here, safety data on RCVI are underreported with the majority of studies providing no or insufficient safety data to conclude that RCVI is a safe method for cell delivery in the heart. Safety and mortality data are provided in Table 3.

Table 3 Safety and mortality data

\begin{tabular}{|c|c|c|c|c|}
\hline & Study & Species & Reported safety aspects & Mortality related to retrograde infusion procedure \\
\hline \multirow[t]{8}{*}{ Small animals } & Di Lascio [10] & Rat & No arrhythmias, described as safe & $16,7 \%(11 / 66)$ probably related to thoracotomy) \\
\hline & Fukushima [11] & Rat & $\begin{array}{l}\text { More VPC and VT in IM group vs RCVI group, } \\
\text { described as safe }\end{array}$ & RCVI: $5.7 \%$ (2/35) vs IM: $5.9 \%(2 / 34)$ \\
\hline & Fukushima [12] & Rat & $\begin{array}{l}\text { More VPC and VT in IM group vs RCVI group, } \\
\text { described as safe }\end{array}$ & RCVI: $8.2 \%$ (4/49) vs IM: $8.3 \%$ (4/48) \\
\hline & Huang [13] & Rat & ns & ns \\
\hline & Huang [14] & Rat & No arrhythmias & $\begin{array}{l}\text { conventional technique: } 42.9 \%(3 / 7) \text { modified } \\
\text { technique: } 0\end{array}$ \\
\hline & Suzuki [15] & Rat & No arrhythmias, described as safe & $\begin{array}{l}29 \%(18 / 62) \text { within } 24 \mathrm{~h} \text {, probably due to } \\
\text { acute heart failure }\end{array}$ \\
\hline & Suzuki [16] & Rat & No arrhythmias & $0 \%$ \\
\hline & Zakharova [17] & Rat & ns & $0 \%$ \\
\hline \multirow[t]{13}{*}{ Large animals } & Pogue [18] & Dog & $\begin{array}{l}\text { Transient AF during procedure in } 6 / 15 \mathrm{dogs} \text {, } \\
\text { described as safe }\end{array}$ & $0 \%$ \\
\hline & Sun [19] & Dog & ns & $0 \%$ \\
\hline & Wang [20] & Dog & $\begin{array}{l}\text { No arrhythmias, no cardiac tamponade, described } \\
\text { as safe }\end{array}$ & $0 \%$ \\
\hline & Formigli [21] & Pig & ns & $0 \%$ \\
\hline & Hagikura [22] & Pig & No arrhythmias, described as safe & $0 \%$ \\
\hline & Hong [23] & Pig & No MVO, described as safe & $0 \%$ \\
\hline & Hou [24] & Pig & ns & $0 \%$ \\
\hline & Kupatt [9] & Pig & ns & ns \\
\hline & $\mathrm{Lu}[25]$ & Pig & ns & ns \\
\hline & Prifti [26] & Pig & No arrhythmias, described as safe & $0 \%$ \\
\hline & Sato [27] & Pig & ns & $0 \%$ \\
\hline & Vicario $[28]$ & Pig & No arrhythmias & ns \\
\hline & Yokoyama [29] & Pig & Described as safe & ns \\
\hline \multirow[t]{6}{*}{ Clinical trials } & Patel [30] & Human & $\begin{array}{l}\text { Rise in cardiac enzymes in some patients, no } \\
\text { arrhythmias associated with RCVI, described } \\
\text { as safe }\end{array}$ & $0 \%$ \\
\hline & Silva [31] & Human & Rise in cardiac enzymes in some patients & $0 \%$ \\
\hline & Tuma [33] & Human & $\begin{array}{l}\text { No rise in cardiac enzymes, no arrhythmias, no } \\
\text { pericardial effusion, described as safe }\end{array}$ & $0 \%$ \\
\hline & Tuma [32] & Human & $\begin{array}{l}\text { No arrhythmias, rise in cardiac enzymes in all } \\
\text { patients, no evidence of CS leak or damage, } \\
\text { described as safe }\end{array}$ & $0 \%$ \\
\hline & Vicario [34] & Human & No arrhythmias, described as safe & $0 \%$ \\
\hline & Vicario [35] & Human & No arrhythmias, described as safe & $0 \%$ \\
\hline
\end{tabular}

$V P C$ ventricular premature contraction, $V T$ ventricular tachycardia, $I M$ intramyocardial injection, $R C V I$ retrograde coronary venous infusion, $n s$ not specified, $A F$ atrial fibrillation, $M V O$ microvascular obstruction, $C S$ coronary sinus 


\section{Efficiency Measures}

\section{Retention Rate}

Preclinical Experience The therapeutic benefit of cell therapy is in part based on the retention of cells in the heart. In total, eight preclinical studies provide data on the percentage of administered cells that retain in the heart after RCVI (Table 4). Different methods are used to determine cardiac retention of cells. One method is the use of real-time polymerase chain reaction for the Y-chromosome-specific Sry gene to detect the amount of transplanted male cells in female subjects. Other methods include administration of $\beta$ galactosidase-expressing cells, or to label cells radioactively with ${ }^{111}$ Indium or $\mathrm{Tc}^{99 \mathrm{~m}}$-hexamethylpropylenamineoxime for quantitative analysis using scintigraphy. The retention rates show a high degree of heterogeneity that can partially be explained by differences in animal model, disease model, cell type, infusion time point, follow-up time point, and quantification technique. Most studies report a retention $\leq 10 \%$ and two studies report a remarkably higher retention of respectively $31.4 \pm 4.8$ and $29.8 \pm 6.9 \%[15,16]$. The latter studies applied an indirect measurement of retention by using $\beta$ galactosidase-expressing cells, and comparing the level of $\beta$ galactosidase activity to the standard curve. One study used a method to optimize retention (magnetic targeting) that resulted in an increase of retention from approximately $2 \%$ after routine RCVI to $8.5 \%$ with magnetic targeting [13]. It should be noted that the three large animal experiments $[9,23,24]$ consist of very small sample sizes. RCVI appeared to be either inferior to $[23,24]$ or equal to $[11,12]$ IM injection or IC infusion regarding cell retention. Retention rates in Table 4 are presented as the percentage of total administered cells that is retained in the heart. In one study [23], retention of cells in the heart was reported as a percentage of cells retained in five major thoracoabdominal organs. We converted the data to a percentage of total administered cells that are retained in the heart in order to achieve comparability between studies. If retention of cells was measured at multiple time points, we reported retention at the first time point, because retention decreased in time in the majority of these studies. A decrease was not seen in three studies $[15,16,23]$. This can be explained by the fact that two of these studies used expression of $\beta$-galactosidase as a measure of cardiac cell retention $[15$, 16]. Increased expression of $\beta$-galactosidase over time was attributed to proliferation of administered cells. The third article [23] presented the retention of cells in the heart as a percentage of the total retention in five major organs. A possible explanation for the increase in retention at a later time point could be that the decrease in the number of cells in the heart was relatively less than the decrease in the number of cells in the five major organs, making this decrease in the heart look like an increase [23].

Clinical Experience Retention of cells in the heart was determined in one clinical trial, showing inferiority of RCVI versus

Table 4 Retention of cells in the heart

\begin{tabular}{|c|c|c|c|c|c|c|c|c|c|c|}
\hline & \multirow[t]{2}{*}{ Study } & \multirow[t]{2}{*}{ Species } & \multirow[t]{2}{*}{ \# } & \multirow{2}{*}{$\begin{array}{l}\text { Retention } \\
\text { method }\end{array}$} & \multirow{2}{*}{$\begin{array}{l}\text { Retention } \\
\text { time point }\end{array}$} & \multicolumn{5}{|c|}{ Application method } \\
\hline & & & & & & RCVI retention & IC retention & IM retention & $\begin{array}{l}\text { Peripheral IV } \\
\text { retention }\end{array}$ & $\begin{array}{l}\text { Sign } \\
\text { comparison }\end{array}$ \\
\hline \multirow[t]{5}{*}{ Small animals } & Fukushima [11] & Rat & 35 & Sry & 3 days & $1.84 \pm 0.27 \%$ & - & $1.45 \pm 0.27 \%$ & - & ns \\
\hline & Fukushima [12] & Rat & 85 & Sry & 3 days & $10 \pm 5 \%$ & - & $14 \pm 5 \%$ & - & $\mathrm{ns}$ \\
\hline & Huang [13] & Rat & 90 & Sry & $24 \mathrm{~h}$ & $2 \% / 8.5 \%^{\mathrm{a}}$ & - & - & - & $P<0.001^{\mathrm{d}}$ \\
\hline & Suzuki [16] & Rat & 20 & $\beta$-galactosidase & $10 \mathrm{~min}$ & $31.4 \pm 4.8 \%$ & - & - & - & na \\
\hline & Suzuki [15] & Rat & 62 & $\beta$-galactosidase & $10 \min$ & $29.8 \pm 6.9 \%$ & - & - & - & na \\
\hline \multirow[t]{3}{*}{ Large animals } & Hong [23] & Pig & 7 & Radiolabel & $1 \mathrm{~h}$ & $\pm 8 \%{ }^{\mathrm{c}}$ & $\pm 25 \%^{\mathrm{c}}$ & - & - & $P=0.037$ \\
\hline & Hou [24] & Pig & 5 & Radiolabel & $1 \mathrm{~h}$ & $3.2 \pm 1 \%$ & $2.6 \pm 0.3 \%$ & $11.3 \pm 3 \%$ & - & Not sign ${ }^{\mathrm{b}}$ \\
\hline & Kupatt [9] & Pig & 6 & Radiolabel & $1 \mathrm{~h}$ & $2.7 \%$ & - & - & $0.5 \%$ & ns \\
\hline Clinical trials & Silva [31] & Human & 9 & Radiolabel & $4 \mathrm{~h}$ & $4.62 \%$ & $16.14 \%$ & - & - & $P=0.01$ \\
\hline
\end{tabular}

In case retention was not measured as $\%$ of total administered dose (e.g., as a $\%$ of uptake in major organs), we calculated the retention $\%$ of total administered dose. This was the case in one study [23]

Sry polymerase chain reaction for the Y-chromosome-specific Sry gene, $\beta$-galactosidase presence of $\beta$-galactosidase-expressing cells, radiolabel retention measured by scintigraphy after radiolabeled cell infusion, $R C V I$ retrograde coronary sinus/venous infusion, $I C$ intracoronary infusion, $I M$ intramyocardial injection, $I V$ intravenous, $n s$ not specified, $n a$ not applicable, \# number of subjects

${ }^{\text {a }} 2 \%$ in case of normal delivery, $8.5 \%$ in case of magnetic targeting

${ }^{\mathrm{b}}$ Comparison between RCVI infusion and IM retention

${ }^{\mathrm{c}}$ Corrected for total injected dose

${ }^{\mathrm{d}}$ Normal delivery versus magnetic targeting 
IC infusion [31]. Cells labeled with $\mathrm{Tc}^{99 \mathrm{~m}}$ hexamethylpropylenamineoxime were used to assess retention in the heart. Just like the three pig studies, sample size was small and retention rates were comparable $[9,23,24]$.

\section{Functional Outcomes}

The goal of cardiac reparative therapy is improvement of cardiac function or decrease of disease characteristics such as angina complaints in order to improve quality of life and decrease mortality. Here, we focused on the effect of cell administration on (1) LVEF (AMI, CMI, CHF), (2) improvement on the Canadian Cardiovascular Society scale (CSS) (CRA), and (3) myocardial perfusion (CRA).

Preclinical Experience Most of the preclinical studies that reported changes in LVEF (12/15) showed a significant increase in LVEF versus baseline and/or controls. Three studies only showed improvement of LVEF when cells were combined with growth factors [22] or no effects on LVEF at all $[18,19]$.

Clinical Experience Three out of four clinical studies reported significant improvement of LVEF. The study that did not show improvement of LVEF after RCVI compared IC infusion with RCVI and reported that patients receiving cells through IC infusion did show improvement in LVEF [31]. The difference in cell retention between IC infusion and RCVI in these patients might be the explanation for this difference in functional outcome. Two other studies show comparable retention rates between IM injection and RCVI and both groups show comparable functional gains $[11,12]$. In case of CRA, changes in CCS scale and improvement in myocardial perfusion were reported [33-35].

In the majority of cases, cells administered with RCVI are able to effectuate improvement of cardiac function in a range of different experimental models. An overview of functional outcomes is presented in Online Resource 2.

\section{Discussion}

Cell delivery strategies should meet two important demands. First and foremost, the technique should be safe. Second, it should be effective in delivering cells to the heart. In this paper, we provided an overview of RCVI.

There is a high degree of heterogeneity regarding technical aspects of RCVI both between and within species. Furthermore, roughly $20 \%$ of studies do not adequately describe procedural characteristics, which hampers the possibility to repeat these experiments technically.

The main finding is that relevant data regarding technique and safety are poorly reported. For instance, $30 \%$ of included studies do not report on safety aspects of RCVI at all, while
$33 \%$ only report absence of arrhythmias without mentioning other safety parameters. Only a limited number of studies provide more in-depth safety information regarding RCVI. The six clinical trials included in this overview report cardiac enzyme rise as the only safety issue associated with RCVI and show no arrhythmias associated with RCVI, no development of pericardial fluid, and no sustained damage to the CS after RCVI. It is understandable that the first priority of research focused on cell therapy lies with validating the effectiveness of cell therapy in itself. From this perspective, it is logical that some studies do not report on safety of delivery because this was not the purpose of the study. Nevertheless, due to the poor reporting of safety aspects, we cannot make an accurate assessment of the safety profile of RCVI.

However, retrograde accessing of the coronary venous system has been performed for a long time in the field of cardiac surgery in a great number of patients. With retrograde cardioplegia (RC), the myocardium is retrogradely perfused during cardiac surgery to induce cardiac arrest and protect the myocardium. With RC, a balloon-catheter is used to occlude the opening of the CS, in a way comparable to RCVI. RC is reported to be safe, with injury to the CS occurring in 0.06 to $0.6 \%$ of patients [36, 37], resulting in formation of hematoma on the atrioventricular groove, perforation of the CS wall, pericardial effusion, or laceration of the right ventricle or CS [37-40]. These data would suggest that the technical part of RCVI, namely the insertion of a balloon-tipped catheter in the CS followed by infusion of fluid, should be safe.

Cells delivered through RCVI are able to improve cardiac function and alleviate angina symptoms. However, in terms of cell retention, the data suggest that RCVI is a limitedly effective delivery strategy for cell therapy. In fact, IC infusion and IM injection show either higher or equal retention rates. It is likely that inferior retention rates decrease the efficacy of RCVI.

Due to the limited number of studies included in this review, we cannot conclude that RCVI is favorable in certain disease types or that certain cell types performed better than others in the included studies.

In conclusion, the available data on technical and safety aspects of RCVI are insufficient and incomplete. Furthermore, retention data show inferior results compared to IC infusion and IM injection. We conclude that at present, there are not enough arguments to proceed with this technique in the clinical arena. Well-designed confirmatory studies on retention rates and safety data are required to proceed with RCVI in the future.

Funding This research is part of Cardiovasculair Onderzoek Nederland (grant number: CVON2011-2012), an initiative of the Dutch Heart Foundation, Netherlands Federation of University Medical Centers (NFU), Royal Netherlands Academy of Arts and Science (KNAW), and 
Nederlandse Organisatie voor Wetenschappelijk Onderzoek/Nederlandse Organisatie voor Gezondheidsonderzoek en Zorginnovatie (NWO/ ZonMW).

\section{Compliance with Ethical Standards}

Conflict of Interest The authors declare that they have no conflict of interest.

Ethical Approval This article does not contain any studies with human participants or animals performed by any of the authors.

Open Access This article is distributed under the terms of the Creative Commons Attribution 4.0 International License (http:// creativecommons.org/licenses/by/4.0/), which permits unrestricted use, distribution, and reproduction in any medium, provided you give appropriate credit to the original author(s) and the source, provide a link to the Creative Commons license, and indicate if changes were made.

\section{References}

1. Fisher, S. A., Zhang, H., Doree, C., Mathur, A., \& Martin-Rendon, E. (2015). Stem cell treatment for acute myocardial infarction. Cochrane Database of Systematic Review (9), Cd006536. doi: https://doi.org/10.1002/14651858.CD006536.pub4.

2. Fisher, S. A., Doree, C., Mathur, A., Taggart, D. P., \& MartinRendon, E. (2016). Stem cell therapy for chronic ischaemic heart disease and congestive heart failure. Cochrane Database of Systematic Reviews, 12, Cd007888. https://doi.org/10.1002/ 14651858.CD007888.pub3.

3. van den Akker, F., Feyen, D. A., van den Hoogen, P., van Laake, L. W., van Eeuwijk, E. C., Hoefer, I., et al. (2017). Intramyocardial stem cell injection: go(ne) with the flow. European Heart Journal, 38(3), 184-186. https://doi.org/10.1093/eurheartj/ehw056.

4. van Slochteren, F. J., van Es, R., Gyongyosi, M., van der Spoel, T. I., Koudstaal, S., Leiner, T., et al. (2016). Three dimensional fusion of electromechanical mapping and magnetic resonance imaging for real-time navigation of intramyocardial cell injections in a porcine model of chronic myocardial infarction. The International Journal of Cardiovascular Imaging, 32(5), 833-843. https://doi.org/10. 1007/s10554-016-0852-x.

5. Vulliet, P. R., Greeley, M., Halloran, S. M., MacDonald, K. A., \& Kittleson, M. D. (2004). Intra-coronary arterial injection of mesenchymal stromal cells and microinfarction in dogs. Lancet, 363(9411), 783-784. https://doi.org/10.1016/s0140-6736(04) 15695-x.

6. Suzuki, K., Brand, N. J., Smolenski, R. T., Jayakumar, J., Murtuza, B., \& Yacoub, M. H. (2000). Development of a novel method for cell transplantation through the coronary artery. Circulation, 102(19 Suppl 3), Iii359-Iii364.

7. Freyman, T., Polin, G., Osman, H., Crary, J., Lu, M., Cheng, L., et al. (2006). A quantitative, randomized study evaluating three methods of mesenchymal stem cell delivery following myocardial infarction. European Heart Journal, 27(9), 1114-1122. https://doi. org/10.1093/eurheartj/ehi818.

8. Moreira Rde, C., Haddad, A. F., Silva, S. A., Souza, A. L., Tuche, F. A., Oliveira, M. A., et al. (2011). Intracoronary stem-cell injection after myocardial infarction: microcirculation sub-study. Arquivos Brasileiros de Cardiologia, 97(5), 420-426.

9. Kupatt, C., Hinkel, R., Lamparter, M., von Bruhl, M. L., Pohl, T., Horstkotte, J., et al. (2005). Retroinfusion of embryonic endothelial progenitor cells attenuates ischemia-reperfusion injury in pigs: role of phosphatidylinositol 3-kinase/AKT kinase. Circulation, $112(9$ Suppl), I117-I122. https://doi.org/10.1161/circulationaha.104. 524801.

10. Di Lascio, G., Harmelin, G., Targetti, M., Nanni, C., Bianchi, G., Gasbarri, T., et al. (2012). Cellular retrograde cardiomyoplasty and relaxin therapy for postischemic myocardial repair in a rat model. Texas Heart Institute Journal, 39(4), 488-499.

11. Fukushima, S., Varela-Carver, A., Coppen, S. R., Yamahara, K., Felkin, L. E., Lee, J., et al. (2007). Direct intramyocardial but not intracoronary injection of bone marrow cells induces ventricular arrhythmias in a rat chronic ischemic heart failure model. Circulation, 115(17), 2254-2261. https://doi.org/10.1161/ circulationaha.106.662577.

12. Fukushima, S., Coppen, S. R., Lee, J., Yamahara, K., Felkin, L. E., Terracciano, C. M., et al. (2008). Choice of cell-delivery route for skeletal myoblast transplantation for treating post-infarction chronic heart failure in rat. PLoS One, 3(8), e3071. https://doi.org/10.1371/ journal.pone.0003071.

13. Huang, Z., Shen, Y., Sun, A., Huang, G., Zhu, H., Huang, B., et al. (2013). Magnetic targeting enhances retrograde cell retention in a rat model of myocardial infarction. Stem Cell Research \& Therapy, 4(6), 149. https://doi.org/10.1186/scrt360.

14. Huang, Z., Shen, Y., Zhu, H., Xu, J., Song, Y., Hu, X., et al. (2013). New coronary retroinfusion technique in the rat infarct model: transjugular cardiac vein catheterization. Experimental Animals, 62(3), 197-203.

15. Suzuki, K., Murtuza, B., Fukushima, S., Smolenski, R. T., VarelaCarver, A., Coppen, S. R., et al. (2004). Targeted cell delivery into infarcted rat hearts by retrograde intracoronary infusion: distribution, dynamics, and influence on cardiac function. Circulation, 110(11 Suppl 1), Ii225-Ii230. https://doi.org/10.1161/01.CIR. 0000138191.11580.e3.

16. Suzuki, K., Murtuza, B., Smolenski, R. T., \& Yacoub, M. H. (2004). Selective cell dissemination into the heart by retrograde intracoronary infusion in the rat. Transplantation, 77(5), 757-759.

17. Zakharova, L., Nural-Guvener, H., Feehery, L., Popovic, S., Nimlos, J., \& Gaballa, M. A. (2014). Retrograde coronary vein infusion of cardiac explant-derived c-Kit+ cells improves function in ischemic heart failure. The Journal of Heart and Lung Transplantation, 33(6), 644-653. https://doi.org/10.1016/j.healun. 2014.03.006.

18. Pogue, B., Estrada, A. H., Sosa-Samper, I., Maisenbacher, H. W., Lamb, K. E., Mincey, B. D., et al. (2013). Stem-cell therapy for dilated cardiomyopathy: a pilot study evaluating retrograde coronary venous delivery. The Journal of Small Animal Practice, 54(7), 361-366. https://doi.org/10.1111/jsap.12098.

19. Sun, Q. W., Zhen, L., Wang, Q., Sun, Y., Yang, J., Li, Y. J., et al. (2016). Assessment of retrograde coronary venous infusion of mesenchymal stem cells combined with basic fibroblast growth factor in canine myocardial infarction using strain values derived from speckle-tracking echocardiography. Ultrasound in Medicine \& Biology, 42(1), 272-281. https://doi.org/10.1016/j.ultrasmedbio. 2015.09.010.

20. Wang, X., Zhen, L., Miao, H., Sun, Q., Yang, Y., Que, B., et al. (2015). Concomitant retrograde coronary venous infusion of basic fibroblast growth factor enhances engraftment and differentiation of bone marrow mesenchymal stem cells for cardiac repair after myocardial infarction. Theranostics, 5(9), 995-1006. https://doi.org/10. 7150/thno.11607.

21. Formigli, L., Perna, A. M., Meacci, E., Cinci, L., Margheri, M., Nistri, S., et al. (2007). Paracrine effects of transplanted myoblasts and relaxin on post-infarction heart remodelling. Journal of Cellular and Molecular Medicine, 11(5), 1087-1100. https://doi. org/10.1111/j.1582-4934.2007.00111.x.

22. Hagikura, K., Fukuda, N., Yokoyama, S., Yuxin, L., Kusumi, Y., Matsumoto, T., et al. (2010). Low invasive angiogenic therapy for 
myocardial infarction by retrograde transplantation of mononuclear cells expressing the VEGF gene. International Journal of Cardiology, 142(1), 56-64. https://doi.org/10.1016/j.ijcard.2008. 12.108 .

23. Hong, S. J., Hou, D., Brinton, T. J., Johnstone, B., Feng, D., Rogers, P., et al. (2014). Intracoronary and retrograde coronary venous myocardial delivery of adipose-derived stem cells in swine infarction lead to transient myocardial trapping with predominant pulmonary redistribution. Catheterization and Cardiovascular Interventions, 83(1), E17-E25. https://doi.org/10.1002/ccd.24659.

24. Hou, D., Youssef, E. A., Brinton, T. J., Zhang, P., Rogers, P., Price, E. T., et al. (2005). Radiolabeled cell distribution after intramyocardial, intracoronary, and interstitial retrograde coronary venous delivery: implications for current clinical trials. Circulation, 112(9 Suppl), I150-I156. https://doi.org/10.1161/circulationaha. 104.526749 .

25. Lu, F., Zhao, X., Wu, J., Cui, Y., Mao, Y., Chen, K., et al. (2013). MSCs transfected with hepatocyte growth factor or vascular endothelial growth factor improve cardiac function in the infarcted porcine heart by increasing angiogenesis and reducing fibrosis. International Journal of Cardiology, 167(6), 2524-2532. https:// doi.org/10.1016/j.ijcard.2012.06.052.

26. Prifti, E., Di Lascio, G., Harmelin, G., Bani, D., Briganti, V., Veshti, A., et al. (2016). Cellular cardiomyoplasty into infracted swine's hearts by retrograde infusion through the venous coronary sinus: An experimental study. Cardiovascular Revascularization Medicine, 17(4), 262-271. https://doi.org/10.1016/j.carrev.2016. 02.008 .

27. Sato, T., Iso, Y., Uyama, T., Kawachi, K., Wakabayashi, K., Omori, Y., et al. (2011). Coronary vein infusion of multipotent stromal cells from bone marrow preserves cardiac function in swine ischemic cardiomyopathy via enhanced neovascularization. Laboratory Investigation, 91(4), 553-564. https://doi.org/10.1038/labinvest. 2010.202.

28. Vicario, J., Piva, J., Pierini, A., Ortega, H. H., Canal, A., Gerardo, L., et al. (2002). Transcoronary sinus delivery of autologous bone marrow and angiogenesis in pig models with myocardial injury. Cardiovascular Radiation Medicine, 3(2), 91-94.

29. Yokoyama, S., Fukuda, N., Li, Y., Hagikura, K., Takayama, T., Kunimoto, S., et al. (2006). A strategy of retrograde injection of bone marrow mononuclear cells into the myocardium for the treatment of ischemic heart disease. Journal of Molecular and Cellular Cardiology, 40(1), 24-34. https://doi.org/10.1016/j.yjmcc.2005.06. 008.

30. Patel, A. N., Mittal, S., Turan, G., Winters, A. A., Henry, T. D., Ince, H., et al. (2015). REVIVE trial: retrograde delivery of autologous bone marrow in patients with heart failure. Stem Cells Translational
Medicine, 4(9), 1021-1027. https://doi.org/10.5966/sctm.20150070.

31. Silva, S. A., Sousa, A. L., Haddad, A. F., Azevedo, J. C., Soares, V. E., Peixoto, C. M., et al. (2009). Autologous bone-marrow mononuclear cell transplantation after acute myocardial infarction: comparison of two delivery techniques. Cell Transplantation, 18(3), 343-352. https://doi.org/10.3727/096368909788534951.

32. Tuma, J., Carrasco, A., Castillo, J., Cruz, C., Carrillo, A., Ercilla, J., et al. (2016). RESCUE-HF trial: retrograde delivery of allogeneic umbilical cord lining subepithelial cells in patients with heart failure. Cell Transplantation, 25(9), 1713-1721. https://doi.org/10. 3727/096368915x690314.

33. Tuma, J., Fernandez-Vina, R., Carrasco, A., Castillo, J., Cruz, C., Carrillo, A., et al. (2011). Safety and feasibility of percutaneous retrograde coronary sinus delivery of autologous bone marrow mononuclear cell transplantation in patients with chronic refractory angina. Journal of Translational Medicine, 9, 183. https://doi.org/ 10.1186/1479-5876-9-183.

34. Vicario, J., Campos, C., Piva, J., Faccio, F., Gerardo, L., Becker, C., et al. (2004). Transcoronary sinus administration of autologous bone marrow in patients with chronic refractory stable angina Phase 1. Cardiovascular Radiation Medicine, 5(2), 71-76. https:// doi.org/10.1016/j.carrad.2004.06.004.

35. Vicario, J., Campo, C., Piva, J., Faccio, F., Gerardo, L., Becker, C., et al. (2005). One-year follow-up of transcoronary sinus administration of autologous bone marrow in patients with chronic refractory angina. Cardiovascular Revascularization Medicine, 6(3), 99107. https://doi.org/10.1016/j.carrev.2005.08.002.

36. Menasche, P., Subayi, J. B., \& Piwnica, A. (1990). Retrograde coronary sinus cardioplegia for aortic valve operations: a clinical report on 500 patients. The Annals of Thoracic Surgery, 49(4), 556563; discussion 563-554.

37. Kaul, T. K., Fields, B. L., \& Jones, C. R. (2000). Iaterogenic injuries during retrograde delivery of cardioplegia. Cardiovascular Surgery, $8(5), 400-403$.

38. Kurusz, M., Girouard, M. K., \& Brown, P. S., Jr. (2002). Coronary sinus rupture with retrograde cardioplegia. Perfusion, 17(1), 77-80, doi:https://doi.org/10.1191/0267659102pf534cr.

39. Krishnan, S., Papworth, D. P., Farivar, R. S., \& Ueda, K. (2013). Identification of coronary sinus injury by transesophageal echocardiography during placement of a retrograde cardioplegia catheter for minimally invasive cardiac surgery. Anesthesia and Analgesia, $116(3), 560-562$. https://doi.org/10.1213/ANE. $0 \mathrm{~b} 013 \mathrm{e} 31827 \mathrm{bc} 352$.

40. Aigner, C., Wolner, E., \& Mohl, W. (2006). Management of central coronary sinus ruptures using the pericardial patch repair technique. The Annals of Thoracic Surgery, 81(4), 1275-1278. https://doi.org/ 10.1016/j.athoracsur.2005.11.037. 